occurred was 49 for $S 1$ and 90 for S4. The mean number of attacks and SE of the mean for the same sessions were $34.0 \pm 2.8$ and $152.0 \pm 14.6$ for $S 1$ and $S 4$, respectively. The 5-day mean durations of the FR 25 and FR 100 schedule components were, respectively, $6.4 \mathrm{sec}$ and $48.6 \mathrm{sec}$ for $\mathrm{S} 1$ and $5.9 \mathrm{sec}$ and $46.7 \mathrm{sec}$ for $\mathrm{S} 4$.

Visual observation revealed that attacks were primarily directed toward the eyes, head, and throat areas of the target pigeon. Although attacks often included attempts at pulling out bits of rabbit fur, the target pigeon remained essentially undamaged throughout the experiment. Both Ss typically would not proceed to the stuffed model immediately after reinforcement of the FR 25 component. Rather, both birds would first orient themselves in front of the blue response key and then advance to the target bird.

\section{DISCUSSION}

The experiment supports the general observations of Hutchinson, Azrin, \& Hunt (1968) and Gentry (1968) that fixed-ratio food schedules generate concurrent aggressive behavior. The present data also support the finding of Hutchinson et al (1968) that attack behavior increased with increases in the fixed-ratio response requirement. That attack was generated by the FR 100 component but not by the FR 25 component of the multiple schedule suggests that a minimum response requirement and/or minimum reinforcement frequency per unit time is/are necessary for the production of aggressive behavior. It is also possible that the characteristic absence of pausing preceding FR 25 key pecking may have precluded the occurrence of attack in that component. Further analyses are needed.

It is unlikely that attack in the present study was maintained by superstitious reinforcement since attacks were temporally separated from subsequent reinforcement by a minimum of $47 \mathrm{sec}$ for $S 1$ and $41 \mathrm{sec}$ for S4. Furthermore, the occurrence of attack had no effect upon the probability of reinforcement since grain deliveries were dependent upon a specified number of key pecks rather than upon time elapsed since the last reinforcement. Finally, if attack behavior was being superstitiously maintained by grain deliveries, it should occur just before rather than following reinforcement.

The use of a durable inanimate attack object in the present study eliminated the problems encountered with a live target (cf. Azrin et al, 1966). The modified stuffed pigeon suggests a means for further objectifying and standardizing the analysis of aggressive behavior.

REFERENCES

AZRIN, N.H., HAKE, D. F., \& HUTCHINSON, R.
R. Elicitation of aggression by a physical blow. Journal of the Experimental Analysis of Behavior, 1965, 8, 55-57.

AZRIN, N.H., HUTCHINSON, R. R., \& HAKE, D. F. Extinction-induced aggression. Journal of the Experimental Analysis of Behavior, 1966, 9, 191-204.

AZRIN, N. H., HUTCHINSON, R. R., \& SALLERY, R. D. Pain-aggression toward inanimate objects. Journal of the Experimental Analysis of Behavior, 1964, 7, 223-227.

GENTRY, W. D. Fixed-ratio schedule-induced aggression. Joumal of the Experimental Analysis of Behavior, 1968, 11, 813-817.

HUTCHINSON, R. R., AZRIN, N.H., \& HUNT,G. $M$. Attack produced by intermittent reinforcement of a concurrent operant response. Journal of the Experimental Analysis of Behavior, 1968, $11,489-495$.
THOMPSON, T., \& BLOOM, W. Aggressive behavior and exinction-induced response-rate increase. Psychonomic Science, 1966, 5, 335-336.

ULRICH, R. E, \& AZRIN, N. H. Reflexive fighting in response to aversive stimulation. Journal of the Experimental Analysis of Behavior, 1962, 5, 511-520.

\section{NOTES}

1. This research was supported in part by Grant MH-11917 from NIMH to Arizona State University and in part by an Arizona State University graduate research fellowship to the author.

2. I thank Drs. Stanley S. Pliskoff and Aaron J. Brownstein for their assistance.

\title{
Effects of blood-glucose levels on wheel-running activity of food-deprived rats'
}

L. F. JAKUBCZAK, Gerontological Psychology Research Laboratory, Veterans Administration Hospital, Jefferson Barracks, St. Louis, Mo. 63125

The purpose of the two experiments was to determine whether or not changes in blood-glucose level affect wheel-running activity of food-deprived rats. Fructose, sucrose, adrenalin, insulin, and saline were injected into food-deprived rats, and their effects on wheel-running activity determined. Adrenalin and insulin decreased running activity, but fructose and sucrose did not. The results indicated that changes in blood-glucose level per se do not seem to be effective stimuli in the control of running activity of food-deprived rats.

Do changes in blood-glucose level play a role in the initiation or termination of running activity of food-deprived rats? Mayer (1955-56, p. 36) stated that the increased activity characteristic of "hunger" behavior is a frequently observed consequence of the depletion of carbohydrate reserves. Assuming that the glucose can be utilized by the peripheral tissue, eating occurs when blood-glucose utilization is low; as before a meal, and does not occur when it is high (Mayer, 1955-56). Since increases in restless and locomotor activity are correlated with the initiation of episodes of eating (Munn, 1950), changes in BGL may serve as stimuli in the control of activity. The purpose of these experiments was to determine whether or not changes in BGL affect wheel-running activity (RA) of food-deprived rats. The results of such experiments should shed light on one of the internal determinants of RA accompanying food deprivation.

\section{DESIGN}

Experiment 1 was carried out according to a 5 by 3 by 5 design (Type III, Linquist, 1956), representing five injected substances (fructose, sucrose, insulin, adrenalin, and normal saline); three blocks of rats formed on the basis of the amounts of running during the 7 days prior to injection; and five hourly samples of RA. The dependent variable for this and Experiment 2 was the number of wheel revolutions emitted during each successive hour of the experiment.

\section{SUBJECTS}

Forty-five male Sprague-Dawley rats (Holzman, Madison, Wis.) were used. Prior to deprivation, their weight was $298 \mathrm{~g}$ (S.D. $=7$ g; range: $284-311$ ).

\section{PROCEDURE}

The rats were randomly assigned to Wahmann activity wheels, deprived of food, and maintained at $80 \%$ of their initial weight. Water was available ad lib in the living compartment. The rats were locked in the wheel-drum for $6 \mathrm{~h}$ each day. At the end of $6 \mathrm{~h}$, they were removed, weighed, and locked in the living compartments for the remaining $18 \mathrm{~h}$. An hour after being removed from the drum, Ss received their food ration. This procedure was followed for 27 days. On the 28 th day, the rats were locked in the drum at their regular time. Two hours later, they were briefly removed, injected with the appropriate substances, returned to the drum, and locked in. The 


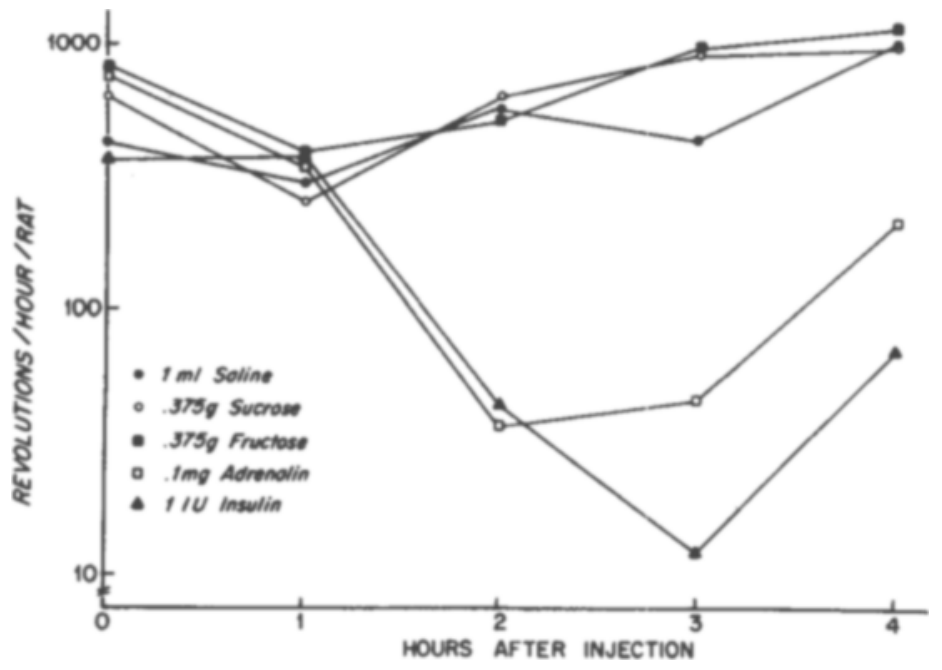

accumulated drum revolutions were recorded hourly. The first hour of activity of the 6-h session was discarded a priori.

The injections consisted of: $0.375 \mathrm{~g}$ L-fructose, Fisher L-95; 0.375 g sucrose, Fisher S-5; $0.0001 \mathrm{~g}$ adrenalin chloride, Parke-Davis No. 88; 1 IU regular insulin, Lilly No. 240; and $1 \mathrm{ml}$ normal saline. The substances were diluted in normal saline, and injected subcutaneously, in 1-cc volume, into the axillary region, and on a per-rat basis. The time of injection was between 10:00 a.m. and 1:00 p.m., and was balanced across treatment groups.

The concentrations of fructose and adrenalin used in this experiment increase blood-glucose levels and decrease ad lib food intake in rats, while that of insulin decreases blood-glucose, and increases ad lib in take of rats (Mayer \& Bates, 1952). Sucrose does not affect blood-glucose levels, is quantitatively excreted, and does not affect food intake. Consequently, it served as a control solution, as did normal saline.

Experiment 2 was carried out in order to assess the effects of dosages of fructose and insulin which differed from those used in Experiment 1. In Experiment 2, 40 of the rats that had been used in Experiment 1 served as Ss. This experiment was carried out according to a 4 by 5 by 5 design (Type III, Linquist, 1956), representing four injected substances $(0.25$ and $0.50 \mathrm{IU}$ insulin, respectively; $0.750 \mathrm{~g}$ L-fructose; and normal saline); five blocks based on substances injected during Experiment 1 (adrenalin, fructose, insulin, saline, sucrose); and five hourly samples of RA. All other procedures were identical with those of Experiment 1.

\section{RESULTS}

In Experiment 1, the main effects of injections $(F=8.40, \mathrm{df}=4 / 44, p<.001)$, levels $(F=4.62, \mathrm{df}=2 / 44, \mathrm{p}<.025)$, and hours $(F=9.28, \mathrm{df}=4 / 120, \mathrm{p}<.001)$, as well as the interaction of injections and hours $(\mathrm{F}=6.39, \mathrm{df}=16 / 120, \mathrm{p}<.001)$, were significant. With increasing time, and regardless of level, adrenalin decreased RA during the first $2 \mathrm{~h}$ after injection, which were followed by a gradual increase of running (Fig. 1). Fructose, however, had no significant effect on RA, nor did sucrose. With increasing time, and regardless of level, insulin decreased RA during the first $3 \mathrm{~h}$, which were followed by an increase of RA.

The results of Experiment 2 were consistent with those of the first experiment. Only the main effects of injections $(\mathrm{F}=29.28, \mathrm{df}=3 / 20)$, hours $(\mathrm{F}=53.9$, $\mathrm{df}=4 / 80$ ), and the interaction of injection and hours $(F=19.26$, $\mathrm{df}=12 / 80)$ were significant $(p<.001)$. The effects of the fructose and the insulin injections were equivalent to those of Experiment 1 . The effects of .25 and $.50 \mathrm{IU}$ of insulin did not differ between themselves, or with the effects of 1 IIJ, used in Experiment 1.

\section{DISCUSSION}

The purpose of this experiment was to determine whether or not changes in $\mathrm{BGL}$ affect RA of food-deprived rats. Although both adrenalin and fructose are known to increase BGL and decrease eating, only adrenalin decreased RA. The RA of the adrenalin groups followed a time course similar to that of BGL. Subcutaneous injection of adrenalin results in peak BGL $2 \mathrm{~h}$ after injection (Mayer \& Bates, 1956), at which time minimum RA was observed (Experiment 1). However, injections of fructose, even in concentrations twice that known to induce hyperglycemia and anorexia (Experiment 2), failed to decrease RA. This suggests that increases in BGL per se do not affect RA, and that the effects of adrenalin on RA are through other mechanisms, such as, for example, changes in CNS arousal. Increased body temperature and decreased stomach contractions, which are effects of both adrenalin and glucagon,
Fig. 1. The effects of injections and hours after injection on wheel-running activity of rats. Note the logarithmic scale on the ordinate.

are unlikely alternative explanations of the effects of adrenalin since 0.1 or $1.0 \mathrm{mg}$ of glucagon, injected 0 or $1 \mathrm{~h}$ before observation, failed to affect RA of food-deprived rats, main tained at $80 \%$ of initial weight. ${ }^{2}$

The doses of insulin used in the present experiments cause a rapid decline in BGL and an increase of food intake within the first hour after injection (Booth \& Pitt, 1968). However, RA did not show any significant effect until $2 \mathrm{~h}$ after injection, and then it decreased. This decrease was probably due to deleterious effects of extreme hypoglycemia on brain metabolism since the Ss manifested comatose symptoms during the third hour. Thus the results suggest that, like increases, decreases in BGL per se do not affect RA.

The results of the present experiment are inconsistent with those of Misanin, Smith, \& Campbell (1964) who found a negative correlation between BGL and stabilimeter activity of food-deprived rats. However, as the authors pointed out, their findings by no means indicated a causal relationship between the two variables. During food deprivation there is a constant drain of blood glucose to the tissues, which if not compensated by dietary intake, results in glycolysis, lipolysis, and proteolysis in order to maintain BGL within normal limits (Tumer, 1960). Products of any or all of these reactions to food deprivation may serve as stimuli for RA. Nevertheless, the results of the present experiment indicate that changes in BGL per se do not seem to be the effective stimuli in the control of RA of food-deprived rats.

\section{REFERENCES}

BOOTH, D. A., \& PITT, M. A. The role of glucose in insulin-induced feeding and drinking. Physiology \& Behavior, 1968, 3, 447-453.

LINDQUIST, E. F. Design and analysis of experiments. Boston: Houghton Mifflin, 1956.

MAYER, J. Regulation of energy intake and body weight: The glucostatic and lipostatic hypothesis. Annals of the New York Academy of Science, 1955-1956, 63, 15-43.

MAYER, J., \& BATES, M. W. Blood glucose and food intake in normal and hypophysectomized, alloxan treated rats. American Journal of Physiology, 1952, 168, 812-819.

MISANIN, J. R., SMITH, N.F., \& CAMPBELL, B, A. Relation between blood sugar level and random activity during food and water deprivation. Psychonomic Science, 1964, 1, 63-64.

MUNN, N. L. Handbook of psychological study of the rat. Boston: Houghton Mifflin, 1950.

TURNER, C. D. General endocrinology. Philadelphia: W. B. Saunders, 1960. NOTES

1. This research was supported by 8200 funds of the U.S. Veterans Administration.

2. L. F. Jakubczak, unpublished manuscript. 